\title{
Osteopontin attenuation of dextran sulfate sodium- induced colitis in mice
}

\author{
Andre Paes Batista da Silva ${ }^{1,2}$, Richard P Ellen ${ }^{1,2}$, Esben S Sørensen ${ }^{3}$, Harvey A Goldberg ${ }^{4}$, Ron Zohar ${ }^{5}$ \\ and Jaro Sodek ${ }^{1,2}$
}

\begin{abstract}
Osteopontin (OPN) is a matricellular cytokine present in most tissues and body fluids; it is known to modulate immune responses. In previous studies using the dextran sulfate sodium (DSS) acute colitis model, we found exacerbated tissue destruction and reduced repair in OPN-null ${ }^{(-/)}$mice compared with wild-type (WT) controls. As OPN is normally present in milk, we hypothesized that administration of OPN may protect the intestines from the adverse effects of experimental colitis. A volume of 20 or $2 \mu \mathrm{g} / \mathrm{ml}$ bovine milk OPN, dissolved in drinking water, was given to mice $24 \mathrm{~h}$ before, and during administration of DSS. Clinical parameters of colitis and neutrophil functions were analyzed as previously reported. Orally administered OPN was absorbed and detected in the colon mucosa by immunohistochemistry. The $20 \mu \mathrm{g} / \mathrm{ml}$ OPN- and DSS-treated WT mice showed 37\% less weight loss and reduced colon shortening and spleen enlargements than control mice $(P<0.05)$. OPN administration also reduced the disease activity index, improved red blood cell counts, and reduced gut neutrophil activity compared with the DSS-treated WT mice that were not administered OPN $(P<0.05)$. Immunohistochemical detection of $\mathrm{F} 4 / 80$-labelled cells (macrophages) was also less frequent. The level of transforming growth factor $\beta 1$ (TGF- $\beta 1$ ) was increased and the levels of pro-inflammatory mediators decreased in colon tissue samples of OPN-treated mice analyzed by ELISA. The reversal of experimental colitis parameters by exogenous OPN was not as robust in the OPN ${ }^{-1-}$ mice. Administration of prokaryotic-expressed recombinant OPN and bovine serum albumin were ineffective. This study shows that administration of a physiological concentration of milk OPN in drinking water ameliorates the destructive host response in DSS-induced acute colitis. Laboratory Investigation (2009) 89, 1169-1181; doi:10.1038/labinvest.2009.80; published online 10 August 2009
\end{abstract}

KEYWORDS: colitis; cytokines; innate immunity; murine; osteopontin

The pathogenesis of inflammatory bowel disease (IBD), which includes ulcerative colitis and Crohn's disease, is believed to involve increased host susceptibility combined with de-regulated immune responses to microbial and dietary antigens. $^{1-3}$ During colitis, neutrophils migrate into the lesion, and they are found within intestinal crypts and at the base of ulcerations, forming crypt abscesses. ${ }^{4}$ Furthermore, several studies have shown that the total number of macrophages increases, including some subpopulations of macrophages that are not normally present in the lamina propria of the intestine. ${ }^{5,6}$ Macrophages together with neutrophils may contribute to intestinal damage by releasing radicals derived from oxygen metabolism ${ }^{7}$ and by secreting pro-inflammatory cytokines and other inflammatory mediators. For our studies, we used the dextran sulfate sodium (DSS)-induced colitis model, which was first described by Okayasu et al, ${ }^{8}$ and which has been extensively used in IBD studies. This murine model shows a deregulated inflammatory response coincident with many pathological changes that are similar to those seen in human ulcerative colitis. ${ }^{8,9}$ Although the lesions are rather uniform and reproducible, the time course and severity of the induced colitis mimics that seen in humans. ${ }^{10}$ Consequently, DSS-induced murine colitis has been recognized as a valuable tool in the identification of potential therapeutic agents, and it is considered to be a sensitive screening system. ${ }^{11}$

Osteopontin (OPN) is a matricellular cytokine present in most tissues and body fluids. It has been suggested that OPN has an important modulatory role in innate immunity, which is reflected by its mucosal protective functions in some

\footnotetext{
${ }^{1}$ CIHR Group in Matrix Dynamics, University of Toronto, Toronto, ON, Canada; ${ }^{2}$ Dental Research Institute, University of Toronto, Toronto, ON, Canada; ${ }^{3}$ Department of Molecular Biology, University of Aarhus, Aarhus, Denmark; ${ }^{4} \mathrm{CIHR}$ Group in Skeletal Development and Remodeling, Department of Biochemistry, School of Dentistry, University of Western Ontario, London, ON, Canada and ${ }^{5}$ Private Practice, Toronto, ON, Canada

Correspondence: Dr RP Ellen, Dental Research Institute, Faculty of Dentistry, University of Toronto, 124 Edward Street, Toronto, ON, Canada M5G 1G6.

E-mail: richard.ellen@dentistry.utoronto.ca

Received 20 March 2009; revised 16 June 2009; accepted 30 June 2009
} 
infectious diseases. ${ }^{12}$ OPN is secreted by dendritic cells, activated macrophages, $\mathrm{T}$ lymphocytes, and subsequently by proliferating fibroblasts during reparative matrix formation. ${ }^{13-15}$ We have shown that OPN is upregulated in epithelial cells of the intestinal mucosa during experimental colitis. ${ }^{16}$ We have also shown that OPN is chemoattractive for neutrophils but not involved in phagocytosis or generation of reactive oxygen species. ${ }^{17}$ Yet, OPN regulates macrophage functions such as migration, activation, and phagocytosis. ${ }^{18-20}$ OPN-mediated initiation of healing appears to be associated with the upregulation of transforming growth factor $\beta 1$ (TGF$\beta 1$ ), which induces restitution of the intestinal epithelial barrier, decreases apoptosis of fibroblasts, and results in increased matrix deposition. ${ }^{21-24}$

Our previous study using the experimental acute colitis model found a greater susceptibility of $\mathrm{OPN}^{-l-}$ mice than wild-type (WT) mice to DSS-induced colitis. ${ }^{16}$ Clinical parameters of colitis, such as weight loss, disease activity scores, colon shortening, and spleen enlargement, were significantly greater in $\mathrm{OPN}^{-1-}$ mice and accompanied by an exacerbation of intestinal tissue damage. Tissue destruction was associated with the persistence of neutrophils and reduced survival of enterocytes. Although OPN has been associated with a detrimental type 1 helper T-cell immune response in other inflammatory diseases, ${ }^{25-29}$ it had important protective functions in our studies of acute colitis. OPN may modulate local immune responses by modifying innate immune cell functions and expression of inflammatory cytokines, thereby attenuating inflammatory tissue damage. This raised the question whether dietary exposure to exogenous OPN may be sufficient to restore an experimental colitis immune response that is less damaging. Therefore, we hypothesized that exogenous delivery of milk OPN in drinking water of mice may protect the colon from the adverse effects of DSS-induced inflammation. Our data show that bovine milk OPN at $20 \mu \mathrm{g} / \mathrm{ml}$ concentration, administered for 8 days in drinking water, ameliorated DSSinduced colitis in mice. It reduced the levels of innate immune cells and pro-inflammatory mediators in the diseased colon and diminished the classic hallmarks of the disease.

\section{MATERIALS AND METHODS}

\section{Source and Biotinylation of OPN}

Samples of bovine milk OPN, containing a mixture of intact OPN and OPN-derived peptides, were prepared as described. ${ }^{30}$ For preparation of recombinant OPN (r-OPN), a pET28a expression vector containing rat OPN cDNA was used to transform Escherichia coli BL21 cells. The recombinant protein was purified by nickel affinity chromatography and fast protein liquid chromatography as previously described for bone sialoprotein. ${ }^{31}$ Biotinylated bovine milk OPN (b-OPN) was prepared as follows: $0.5 \mathrm{mg} /$ $\mathrm{ml}$ of OPN in a 50-mM sodium bicarbonate buffer ( $\mathrm{pH} 8.5)$ was mixed with biotin- $N$-hydroxysuccinimide ester dissolved in dimethyl sulfoxide for $2 \mathrm{~h}$ at $4^{\circ} \mathrm{C}$, desalted on a $10-\mathrm{ml}$ desalting column (PD-10 desalting columns, Amersham Biosciences, Piscataway, NJ, USA) equilibrated in $50 \mathrm{mM}$ ammonium bicarbonate buffer ( $\mathrm{pH}$ 8.5). A dot blot assay with streptavidin-horseradish peroxidase (HRP) was used to confirm the fractions containing OPN. The OPN was dried on a speed vacuum and reconstituted in phosphate-buffered

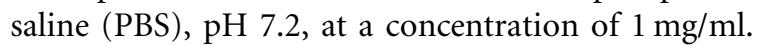

\section{DSS-Induced Experimental Acute Colitis in Mice and Delivery of Exogenous OPN}

Approved animal experiments were conducted according to guidelines established by the Animal Care Committee of the University of Toronto. The generation and initial characterization of $\mathrm{OPN}^{-1-}$ mice was described previously. ${ }^{32}$ The original 129sv F2 mice were subsequently back-crossed $(10 \times)$ into a C57BL/6J background. Polymerase chain reaction (PCR) was used at regular intervals for genotyping of $\mathrm{OPN}^{-1-}$ mice to confirm that the colony had not been contaminated. For these studies, we used adult $\mathrm{OPN}^{-1-}$ males, 8- to 10-week old, and their matched C57BL/6J WT controls. The mice were housed in a specific pathogen-free facility with controlled temperature and light/dark cycles, and fed standard mouse chow pellets. DSS (DSS-36 00050000 MW; MP Biomedical, Aurora, OH, USA) 5\% (wt/vol), dissolved in sterile distilled water, was given for 7 days to induce experimental colitis. ${ }^{9}$ Control animals were given water only, and water consumption was monitored for both animal groups. Bovine milk OPN was dissolved in the drinking water at $20 \mu \mathrm{g} / \mathrm{ml}$, representing the normal physiological concentration in bovine milk, or at $2 \mu \mathrm{g} / \mathrm{ml}$. For short-term experiments to determine whether OPN would be detected in the colon tissues and in the blood after exogenous administration of OPN, a higher dose of $200 \mu \mathrm{g} / \mathrm{ml}$, which approximates the physiological concentration of human milk, was also used. The OPN was continuously given to mice starting $24 \mathrm{~h}$ before administration of the DSS to induce colitis. The mice were killed after 7 days of DSS, which was the 8th day of OPN administration. In one set of experiments, bovine serum albumin (BSA) was used in place of OPN as an exogenous protein control. Similarly, the therapeutic impact of administering prokaryotic-expressed r-OPN, lacking typical post-translational modifications, was compared with that of the bovine milk OPN.

\section{Analysis of Clinical Parameters}

Clinical parameters were analyzed as previously reported. ${ }^{16}$ Among other key variables (body weight, spleen enlargement, colon length, and water consumption), the parameters included variables originally described by Hartmann $e t a^{33}$ as a 'disease activity index (DAI),' based on anal bleeding and the nature of the feces. Individual animal scores between 0 and 3 were used, with ' 0 ' referring to normal stool and no fecal blood and ' 3 ' for liquid stool and/or presence of blood on the cage wall. The mean \pm s.e.m. was determined for each group. 


\section{Detection of b-OPN and Murine OPN in Tissue Sections by Immunohistochemistry}

The b-OPN and DSS were dissolved in the drinking water, and the mice were killed after 7 days of DSS treatment, as described above. The b-OPN was detected in sections of colon tissues by immunohistochemistry as previously described. ${ }^{16}$ Briefly, frozen sections were fixed in $50 \%$ acetone, placed in ethanol for $10 \mathrm{~min}$ and stored at $-20^{\circ} \mathrm{C}$ for 2 days. The sections were incubated with $3 \% \mathrm{H}_{2} \mathrm{O}_{2}$ for $10 \mathrm{~min}$ to eliminate endogenous peroxidase activity and blocked with $1 \%$ BSA for $10 \mathrm{~min}$. The sections were incubated with avidin and biotinylated HRP (Vectastain Universal Elite ABC kit) for $30 \mathrm{~min}$, and then the HRP enzyme activity was visualized by adding the chromogenic substrate 3,3'-diaminobenzidine tetrachloride (DAB; Vector Laboratories, Burlingame, CA, USA) for $10 \mathrm{~min}$, which results in brown staining. The expression of OPN in mouse colons was also examined by immunohistochemical analysis. The sections were incubated overnight with a rabbit anti-porcine OPN antibody, ${ }^{34}$ affinitypurified using recombinant rat OPN, and the sections were incubated with goat anti-rabbit IgG for $30 \mathrm{~min}$.

\section{Plasma b-OPN Quantification}

b-OPN, $20 \mu \mathrm{g} / \mathrm{ml}$ in drinking water, was ingested ad libitum by 12 mice for 8 days. Eight additional mice were selected and treated with $1 \mathrm{ml}$ of 20 or $200 \mu \mathrm{g} / \mathrm{ml} \mathrm{b-OPN}$ by oral gavage. After $4 \mathrm{~h}$, blood was collected from all the mice, and the resulting plasma stored at $-80^{\circ} \mathrm{C}$. A modified sandwich ELISA was used to quantify the amount of b-OPN in the samples. Briefly, $100 \mu \mathrm{l}$ of $4 \mu \mathrm{g} / \mathrm{ml}$ polyclonal rabbit antibody raised against bovine milk OPN was added to the wells of an enhanced protein-binding ELISA plate (Falcon, cat. no. 353279). As a negative control, some wells were left coatingfree. After incubation overnight at $4{ }^{\circ} \mathrm{C}$, the plate was brought to room temperature, the capture antibody solution was removed, and the wells blocked by the addition of $200 \mu \mathrm{l}$ of $0.05 \%$ Tween 20 and 1\% BSA in PBS for $1 \mathrm{~h}$. After washing three times with PBS/Tween, $100 \mu \mathrm{l}$ of a plasma sample was added and incubated for $4 \mathrm{~h}$ at room temperature. The streptavidin-HRP conjugate was used at a dilution of 1:1000 in PBS. The substrate was added and absorbance at $490 \mathrm{~nm}$ determined (Titertek Multiskan reader; Titertek Instruments, Huntsville, AL, USA).

\section{Peripheral Blood Cell Analyses}

Approximately $0.5-1 \mathrm{ml}$ of blood was collected by intracardiac puncture, placed in a labeled vial containing $1000 \mu \mathrm{g} / \mathrm{ml}$ heparin, and transported on ice for hematological analysis to VITA-TECH Laboratories (Toronto, ON, Canada). Blood samples were analyzed for total blood cells and differential white blood cell (WBC) counts, red blood cell (RBC) counts, hemoglobin, hematocrit, mean corpuscular hemoglobin, mean corpuscular volume, and mean corpuscular volume concentration.

\section{Myeloperoxidase Activity}

Myeloperoxidase (MPO) activity was analyzed in gut tissue samples as a surrogate variable to evaluate neutrophil accumulation and activity, using a commercial kit for the o-dianisidine assay (Cytostore, Calgary, AB, USA). Briefly, weighed gut strips that had been washed in PBS and stored at $-80^{\circ} \mathrm{C}$ were thawed, homogenized in a $0.5 \%$ hexadecyltrimethylammonium bromide in $50 \mathrm{mM}$ phosphate buffer ( $\mathrm{pH}$ 6.0), and clarified by centrifugation for $2 \mathrm{~min}$ at $9000 \mathrm{~g}$ at $4^{\circ} \mathrm{C}$. An aliquot of the supernatant was allowed to react with the chromogen (o-dianisidine dihydrochloride) in the presence of potassium phosphate buffer and $1 \% \mathrm{H}_{2} \mathrm{O}_{2}$, as supplied by the manufacturer. The absorbance at $450 \mathrm{~nm}$ was measured immediately by spectrophotometry and again at $60 \mathrm{~s}$ after the addition of the chromogen to determine the reaction rate. Murine bone marrow neutrophils, isolated on a Percoll gradient, served as a positive control. MPO was expressed as the quantity of enzyme in $1 \mathrm{mg}$ tissue that degraded $1 \mu \mathrm{mol} / \mathrm{min}$ of peroxide at $37^{\circ} \mathrm{C}$.

\section{Macrophage Detection Using F4/80 Antibody Staining}

F4/80 antigen expression by macrophages was detected by immunohistochemistry using a rat monoclonal F4/80 antibody (ab6640, Abcam, Cambridge, MA, USA) to label sections of colon tissues. Briefly, frozen sections were fixed in $50 \%$ acetone, placed in ethanol for $10 \mathrm{~min}$ and stored at $-20^{\circ} \mathrm{C}$. The sections were incubated with $3 \% \mathrm{H}_{2} \mathrm{O}_{2}$ for $10 \mathrm{~min}$ to eliminate endogenous peroxidase activity. After blocking with Rodent Block M (cat no. RBM961L, Biocare Medical LLC, Concord, CA, USA) for $30 \mathrm{~min}$, the sections were incubated for $60 \mathrm{~min}$ at room temperature with 1:50 diluted rat anti-mouse F4/80 antibody. The sections were incubated with anti-rat IgG (Rat on Mouse HRP-Polymer Kit, cat no. RT517L, Biocare Medical LLC) for $30 \mathrm{~min}$ and then with the chromogenic substrate (DAB) for $10 \mathrm{~min}$. Mouse spleen was used as the positive control; the primary antibody was omitted for the negative control.

\section{Quantification of TGF- $\beta 1$ and Cytokine Assay}

The colon tissue samples were prepared as described above for the MPO assay, and aliquots were analyzed for TGF- $\beta 1$ content. The TGF- $\beta 1$ concentration was determined by a quantitative sandwich enzyme immunoassay technique using a commercial kit (Quantikine, R\&D Systems, Inc., Minneapolis, $\mathrm{MN}$, USA). In addition, the homogenized gut tissue samples were analyzed with an antibody-based protein array system to quantify secreted pro-inflammatory cytokines, such as granulocyte colony-stimulating factor (G-CSF), interferon gamma (IFN- $\gamma$ ), macrophage colony-stimulating factor (M-CSF), tumor necrosis factor alpha (TNF- $\alpha$ ), monokine induced by gamma-interferon (MIG), regulated on activation normal T cell expressed and secreted (RANTES), using TranSignal ${ }^{\mathrm{TM}}$ Mouse Cytokine Antibody arrays (Panomics, Fremont, CA, USA). Changes in cytokine secretion were evaluated for each sample in relation to the mean density of the negative controls $(0 \%)$ and 
the mean density of the positive controls (100\%), supplied by the manufacturer, on each cytokine array membrane. The values are expressed as the percentage change (mean \pm s.d.).

\section{Statistical Analyses}

Results are expressed as mean \pm s.e.m. Experiments in vivo were carried out at least five times with three or more mice in each group, and analysis of tissues was carried out at least three times. The data were compared using one-way ANOVA analysis with the Bonferroni method as post hoc test. Statistical significance was defined as $P<0.05$. Calculations were carried out using the statistical analysis software SPSS (SPSS, Chicago, IL, USA).

\section{RESULTS}

\section{Absorption of Bovine Milk OPN}

To determine whether bovine milk OPN was absorbed during the course of OPN treatment, $20 \mu \mathrm{g} / \mathrm{ml}$ b-OPN was administered orally, and its concentration in plasma was determined using the ELISA method. b-OPN ingested ad libitum was not detected in the plasma of these mice. However, mice that also received either 20 or $200 \mu \mathrm{g} / \mathrm{ml} \mathrm{OPN}$ by gavage had $\sim 145$ and $\sim 1050 \mathrm{ng} / \mathrm{ml}$ of $\mathrm{b}-\mathrm{OPN}$ in plasma, respectively (Figure 1). No reactivity was detected in the plasma of control mice administered OPN that was not biotinylated, either orally or by gavage.

\section{Milk OPN Detection in Inflamed Colons}

To investigate whether OPN was taken up by the diseased colon tissues, b-OPN was administered to DSS-treated mice. Immunostaining of controls, and sham and DSS-treated WT colon tissue that had been exposed to exogenous non-biotinylated OPN showed only a slight staining in the epithelial cells of the mucosa that may have been due to endogenous

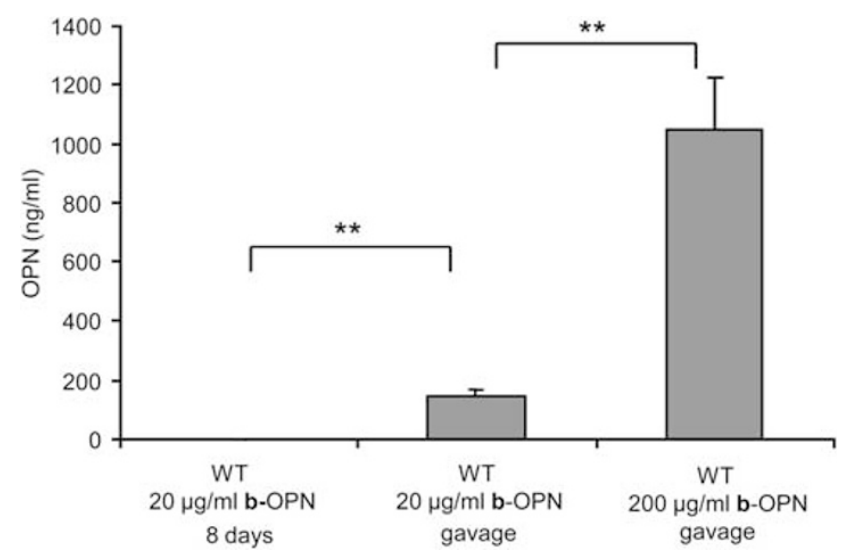

Figure 1 Detection of biotinylated (b-)OPN in peripheral blood. b-OPN was not detected in the plasma of mice administered $20 \mu \mathrm{g} / \mathrm{ml}$ OPN ad libitum in drinking water for 8 days. However, mice that received either 20 or $200 \mu \mathrm{g} / \mathrm{ml}$ OPN by gavage had $\sim 145$ and $\sim 1050 \mathrm{ng} / \mathrm{ml}$ of OPN in plasma, respectively ( $\left.{ }^{*} P<0.001, n=5\right)$, indicating that the OPN can be absorbed through the gut wall. enterocyte biotin (Figure 2a, b, Supplementary Figure S1d, S2a), as immunostaining specific for OPN itself yielded much stronger labeling (Supplementary Figure S2b). No staining was observed in the absence of the streptavidin-HRP complex (Figure 2c, Supplementary Figure S1c). Administration of b-OPN resulted in increased staining within the colon; it was especially intense in the epithelium of the mucosa (Figure 2d) and greater than the staining after exogenous administration of control protein b-BSA (Supplementary Figure S1e). To better establish the architecture of tissue sections analyzed in Figure 2, hematoxylin and eosin staining of sections from comparable tissues was also provided (Supplementary Figure S3a-d). All together, the results of these experiments showed that OPN was retained by the mucosa of the colon after exogenous administration of bovine milk OPN.

\section{Milk OPN has Beneficial Effects on Clinical Outcomes in Experimental Colitis}

Treatment of WT and $\mathrm{OPN}^{-1-}$ mice with DSS produced clinical and histological signs of colitis, as we had reported previously; ${ }^{16}$ yet the DAI scores for WT and OPN mice were not statistically different in the present data set (Supplementary Figure S5). DSS-treated WT mice lost weight from day 4 onward; in contrast, the DSS-treated mice that were administered $20 \mu \mathrm{g} / \mathrm{ml}$ milk OPN lost significantly less weight (Figure 3a; $P<0.05, n=9$ ). The DSS-treated $\mathrm{OPN}^{-1-}$ mice also lost weight; yet, administering them OPN diminished their weight loss only on day $6,(P<0.05, n=9)$. Water consumption measurements showed that DSS-treated mice that received the $20 \mu \mathrm{g} / \mathrm{ml}$ dose of OPN consumed more water (Figure 3b; $P<0.05, n=7$ ). This finding suggests that they were less sick, although their increased water consumption would coincidently also increase their exposure to DSS. The DAI scores based on stool consistency and anal bleeding was $\sim 40 \%$ lower on the sixth and seventh day for the $20 \mu \mathrm{g} / \mathrm{ml}$ OPN group (Figure 3c; $P<0.001, n=9$ ). Spleen enlargement, a marker of systemic inflammation, was calculated in proportion to the body weight. In the DSS-treated WT animals, $20 \mu \mathrm{g} / \mathrm{ml}$ OPN induced a smaller increase in the spleen weight (Figure 3d; $P<0.05, n=9$ ). Similarly, colon length, a morphometric measurement of the degree of colitis, was not as short in the DSS-treated mice that had been given $20 \mu \mathrm{g} / \mathrm{ml}$ OPN as that in the other DSS-treated groups, for both WT and $\mathrm{OPN}^{-1-}$ mice (data not shown). For some clinical parameters measured, the $2 \mu \mathrm{g} / \mathrm{ml}$ dose of OPN tended to induce partially protective effects, although not to the same degree as $20 \mu \mathrm{g} / \mathrm{ml}$ OPN (Figure $3 \mathrm{a}$ and c). For most of the clinical indices analyzed, the administration of exogenous OPN led to the reversal of the measured parameters in DSS-fed WT mice, but to either no effect, or much less of an effect, in DSS-fed $\mathrm{OPN}^{-1-}$ mice.

Heparinized peripheral blood collected by intra-cardiac puncture on day 7 contained lower levels of RBC, hemoglobin, and hematocrit (data not shown) in mice treated 

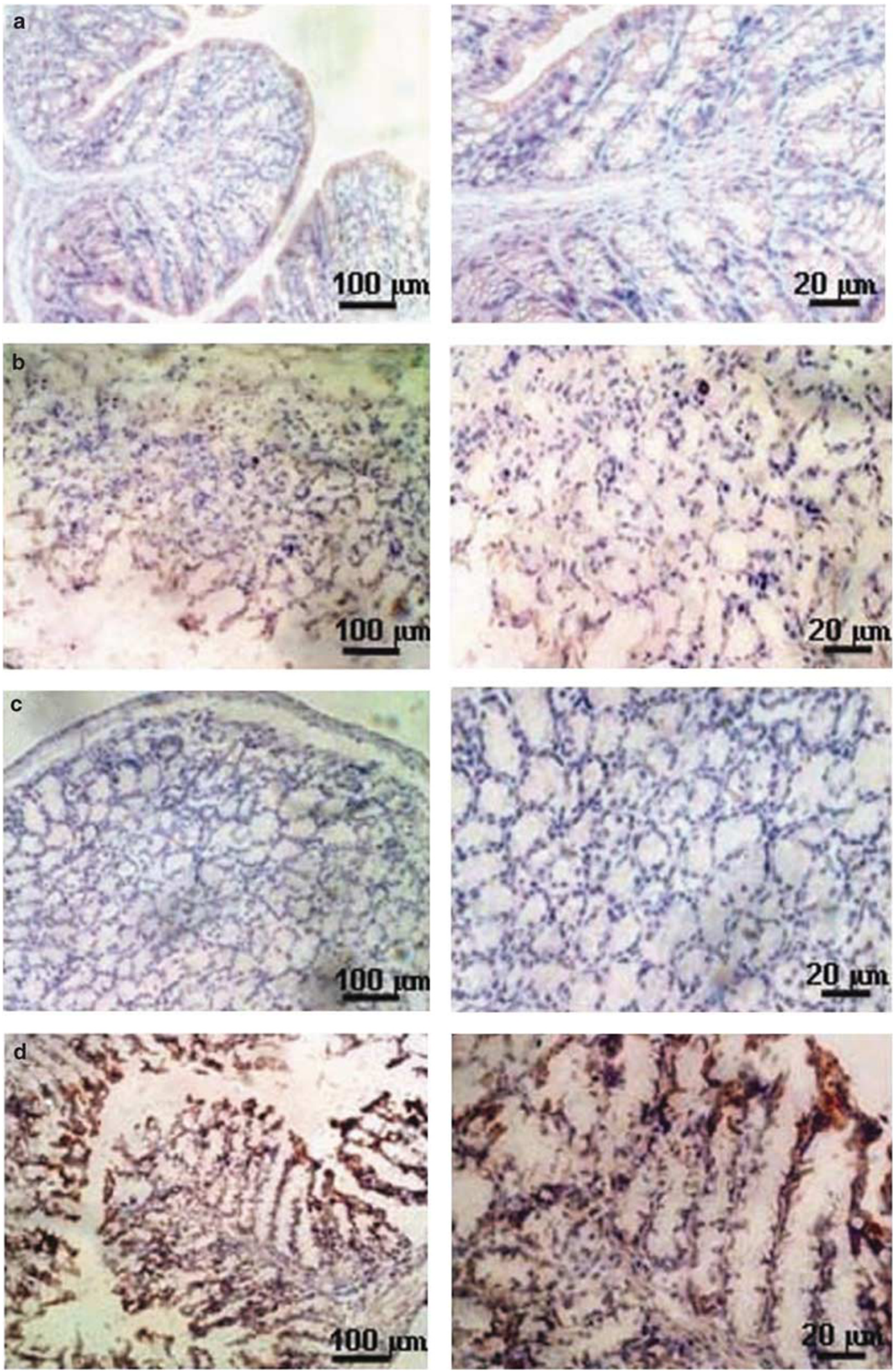

Figure 2 Detection of biotinylated OPN (b-OPN) by immunohistochemistry at low (left column) and higher (right column) magnification. (a and b) Immunostaining of sham and DSS-treated WT colon tissue that was not exposed to bovine b-OPN yielded slight immunostaining in the epithelial cells of the mucosa. (c) No staining in WT DSS-treated colon in the absence of streptavidin-HRP complex. (d) Immunostaining of colon sections of mice that were fed bOPN in drinking water yielded abundant labeling, especially in the epithelial layer of the mucosa. 

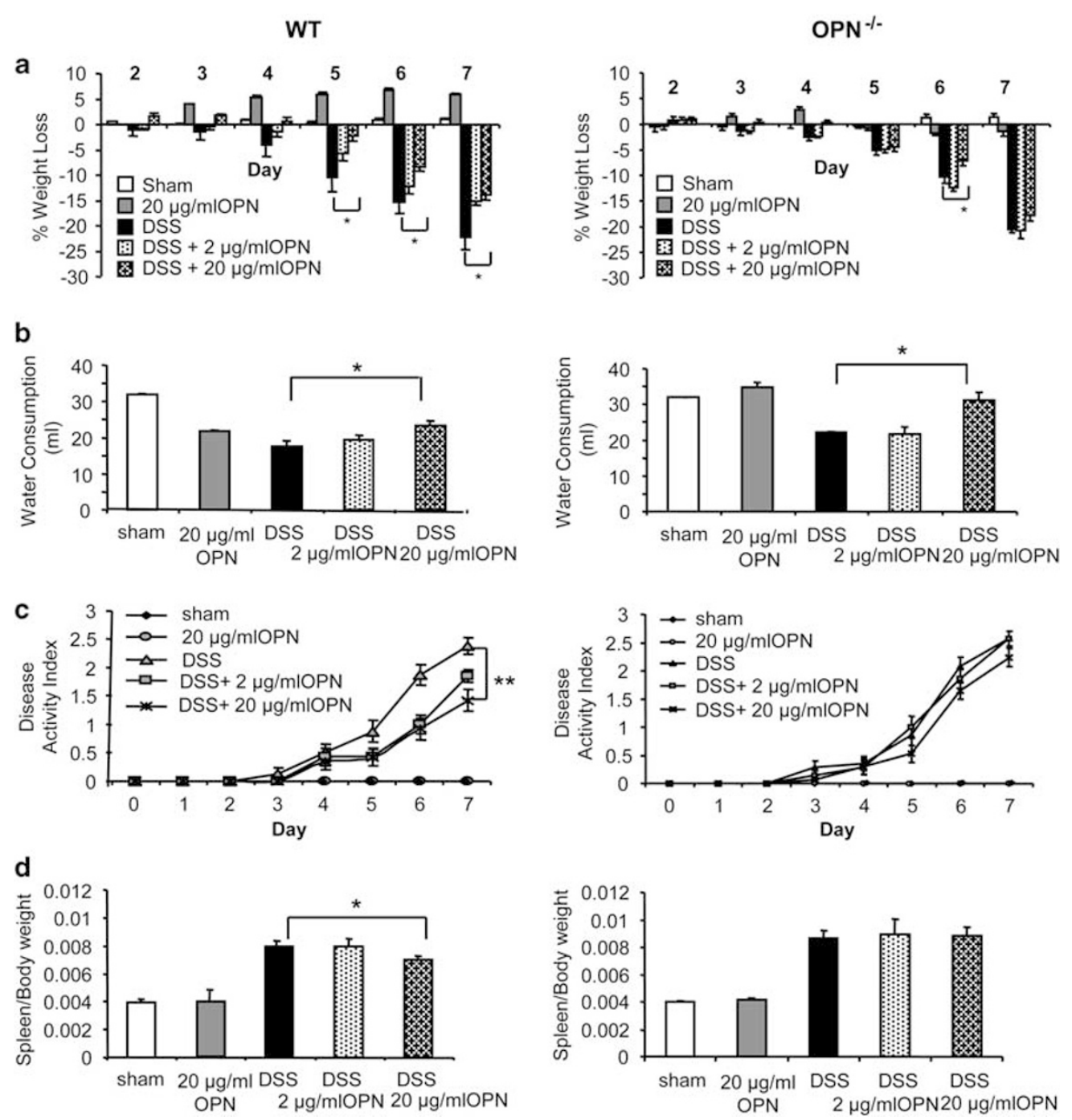

Figure 3 Clinical progression of DSS-induced colitis in WT (left column) and OPN ${ }^{-1-}$ mice (right column) after 8 days administration of milk OPN. (a) DSStreated WT mice administered $20 \mu \mathrm{g} / \mathrm{ml}$ OPN lost significantly less weight than the DSS-treated control mice on days 5,6 and $7\left({ }^{\star} P<0.05, n=9\right)$. The weight loss for the $\mathrm{OPN}^{-1-}$ mice given $20 \mu \mathrm{g} / \mathrm{ml}$ OPN was significantly less than controls only on day $6\left({ }^{*} P<0.05, n=9\right)$. (b) Water consumption measurements showed that OPN-administered mice consumed more water $\left({ }^{*}<<0.05, n=7\right)$. (c) DSS-treated WT mice administered $20 \mu \mathrm{g} / \mathrm{ml}$ milk OPN exhibited DAl scores significantly lower on days 6 and $7(* * P<0.001, n=9)$. No statistically significant differences were found in the OPN ${ }^{-1-}$ mice $(n=9)$. (d) In the DSS-treated WT animals, $20 \mu \mathrm{g} / \mathrm{ml}$ of OPN led to a smaller increase in spleen size $\left({ }^{*} P<0.05, n=9\right)$, which was not seen in the OPN ${ }^{-1-}$ mice $(n=9)$.

with DSS, which is indicative of hemorrhage. Blood from the mice administered $20 \mu \mathrm{g} / \mathrm{ml}$ OPN had greater levels of RBC and hemoglobin (Figure $4 \mathrm{a}$ and $\mathrm{b} ;(25 \%$ increase; $P<0.05$, $n=9$ ), as well as hematocrit increased by $\sim 25 \%$ (data not shown), indicating decreased loss of fecal occult blood. However, the DSS-treated $\mathrm{OPN}^{-1-}$ mice did not exhibit any significant difference in these parameters upon administration of OPN (Figure 4a and b). These data suggest that beneficial effects of OPN in ameliorating the progression of colitis are not as readily achievable in $\mathrm{OPN}^{-1-}$ mice.

Differentiation analysis of WBC counts (Figure 4c-e) showed a statistically significant decrease in the level of neutrophils in DSS-treated mice that were administered $20 \mu \mathrm{g} / \mathrm{ml}$ OPN. The neutrophil count was markedly de- creased by $\sim 43 \%$ (Figure $4 \mathrm{e} ; P<0.05, n=9$ ). In contrast, in the $\mathrm{OPN}^{-1-}$ mice, administration of $20 \mu \mathrm{g} / \mathrm{ml}$ OPN actually increased WBC counts (Figure 4c). Differential analysis showed that both lymphocyte and neutrophil counts were elevated compared with DSS-treated controls (Figure $4 \mathrm{~d}$ and e). OPN Administration Reduces the Destructive Potential
of Neutrophils and Leads to Lower Macrophage Counts
during Experimental Colitis
MPO activity, a potentially tissue-destructive indicator of neutrophil infiltration, was increased markedly in samples of colon tissue from DSS-treated mice, with a greater increase in the colons of $\mathrm{OPN}^{-1-}$ mice (Figure $5 \mathrm{a}$ ). It can be noted that 


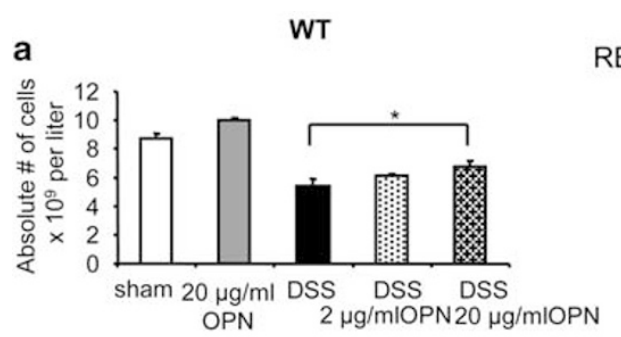

RBC

$\mathrm{OPN}^{-1}$

b
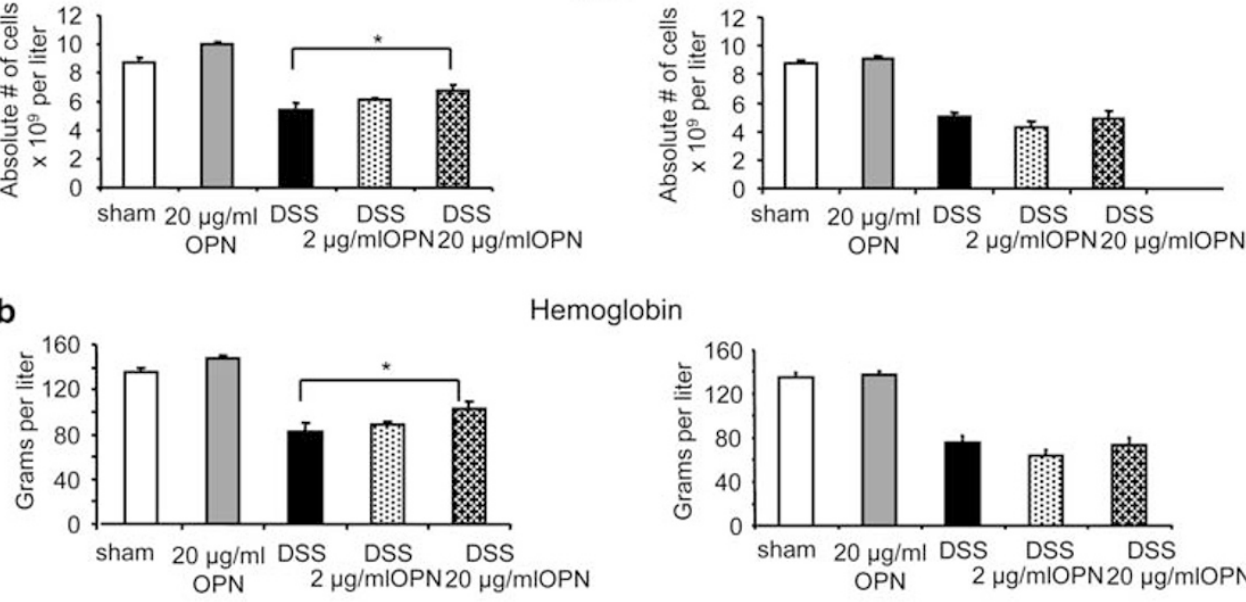

Hemoglobin
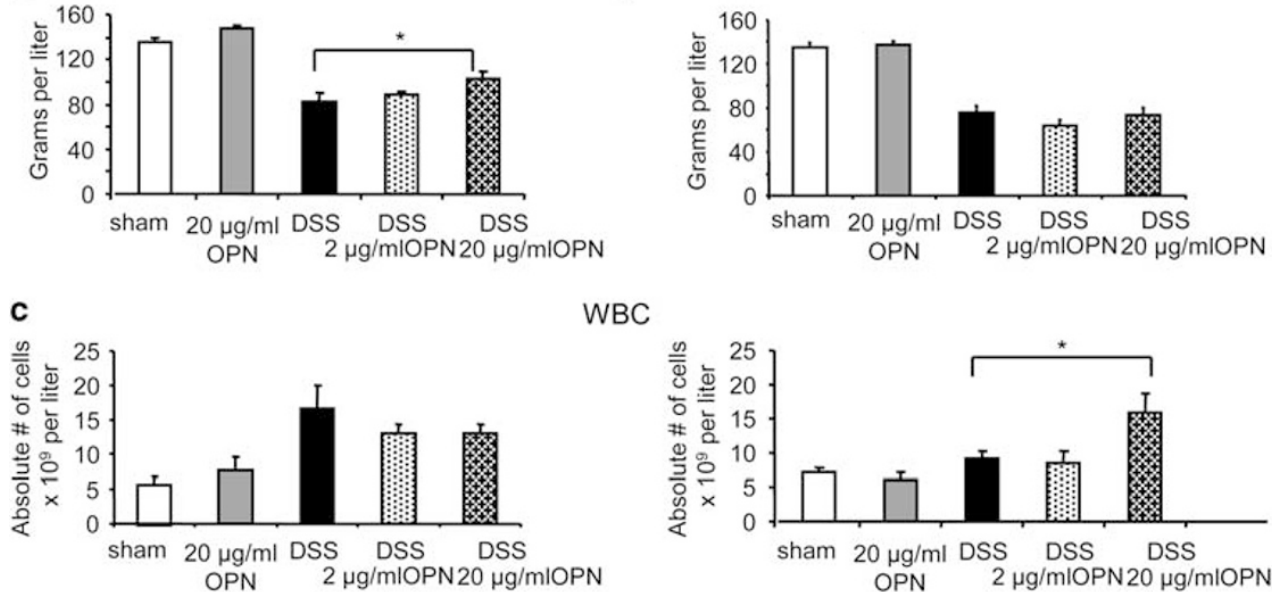

WBC
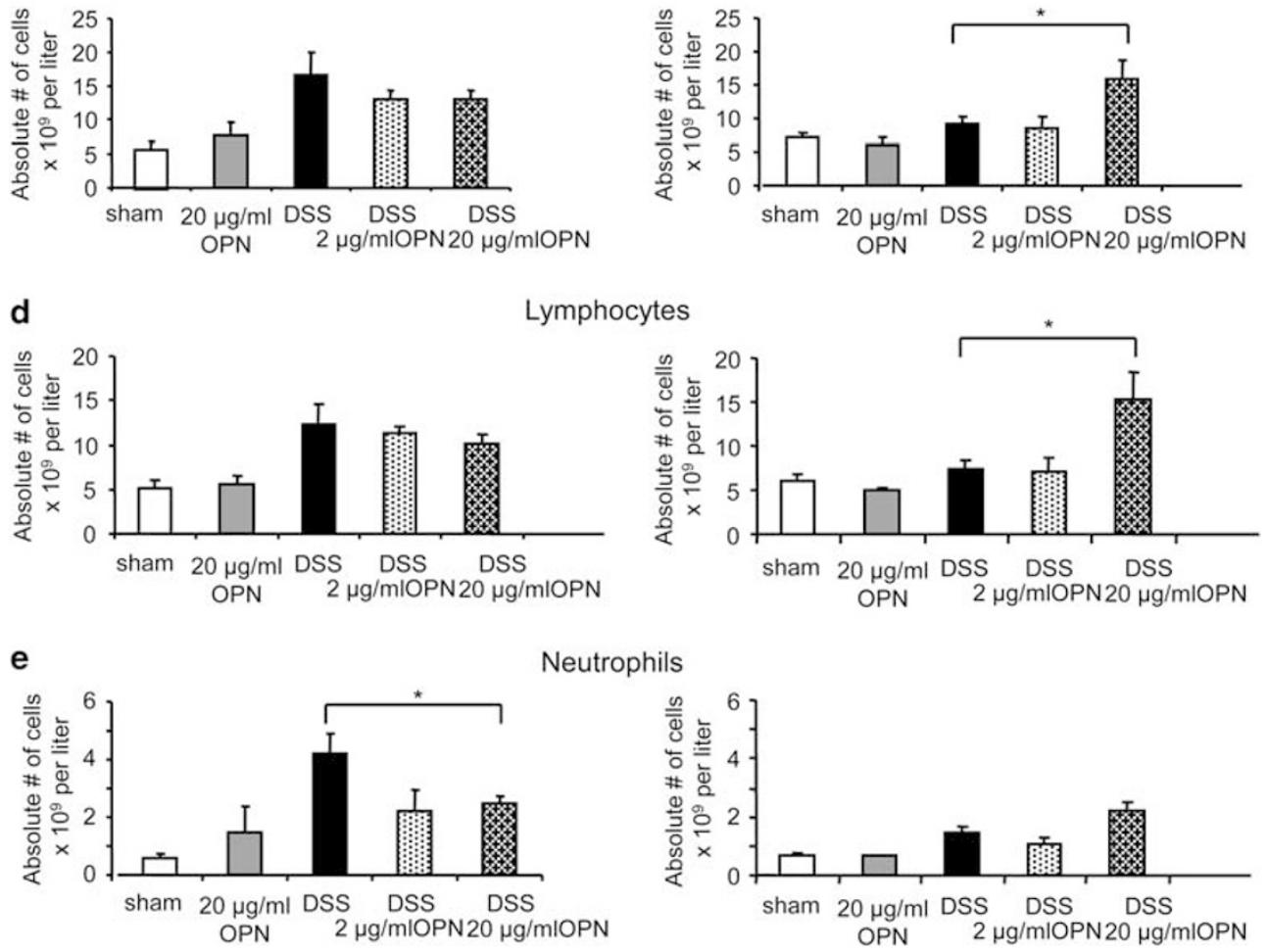

Figure 4 RBC and WBC analysis in the peripheral blood. (a and $\mathbf{b})$ DSS-treated WT mice exhibited low levels of RBC and hemoglobin. The administration of $20 \mu \mathrm{g} / \mathrm{ml}$ led to greater levels of RBC and hemoglobin $\left({ }^{\star} P<0.05, n=9\right)$. DSS-treated OPN ${ }^{-1-}$ mice did not exhibit any significant difference when OPN was administered. (c-e) In the WT mice, OPN intake appeared to reduce the levels of WBC counts from the high levels of WBC seen in the control DSS-induced colitis blood samples. Differential analysis showed that neutrophils were markedly decreased in the OPN $20 \mu \mathrm{g} / \mathrm{ml}$ group $\left({ }^{\star} P<0.05, n=9\right)$. In the OPN ${ }^{-1-}$ mice, the $20 \mu \mathrm{g} / \mathrm{ml}$ dose of OPN led to higher WBC counts. Differential analysis showed that this increase occurred mainly due to lymphocytes $\left({ }^{\star} P<0.05\right.$, $n=9$ ).

MPO was reduced in the colons of the WT mice that had been administered $20 \mu \mathrm{g} / \mathrm{ml}$ OPN (Figure $5 \mathrm{a}, P<0.05, n=7$ ).

Similarly, staining of colon sections with $\mathrm{F} 4 / 80$, a marker for macrophages, found that administration of $20 \mu \mathrm{g} / \mathrm{ml} \mathrm{milk}$ OPN apparently led to decreased macrophage recruitment. In the sham-control WT colon, F4/80 + staining was observed mostly in the submucosa (Figure 5b). As noted in the control
(Figure $5 \mathrm{c}$ ), no staining was observed in the absence of primary antibody. As expected, due to crypt destruction and high levels of pro-inflammatory cytokines, ${ }^{16} \mathrm{~F} 4 / 80$ immunostaining in DSS-treated WT mice showed a large increase in the number of macrophages throughout the mucosa and submucosa (Figure 5d). The administration of $20 \mu \mathrm{g} / \mathrm{ml}$ OPN to DSS-treated mice decreased macrophage 

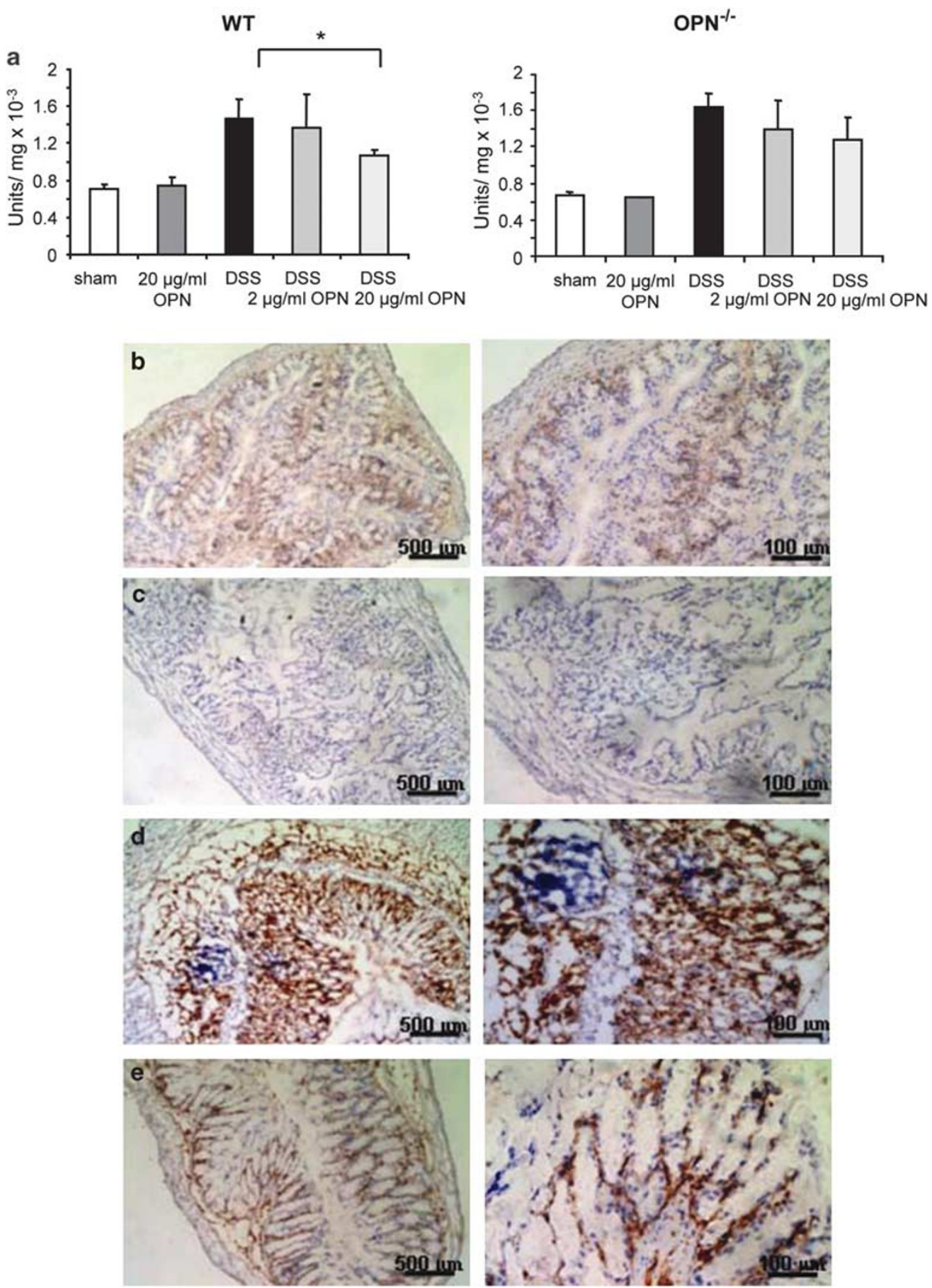

Figure 5 Colon tissue MPO activity and F4/80 immunostaining of colon sections. (a) Myeloperoxidase activity was reduced in the colon of both WT and $\mathrm{OPN}^{-1-}$ mice exposed to the higher concentration of exogenous OPN; yet, significant only in the WT group $\left({ }^{\star} P<0.05, n=7\right)$. (b) Control staining of DSStreated WT colon in the absence of primary antibody. (c) Staining of sham WT colon showing F4/80-positive cells mainly in the submucosa. (d) Immunostaining of DSS-treated WT mice indicating increased infiltration of macrophages in both the mucosa and submucosa. (e) Staining showing decreased macrophage infiltration in OPN-administered DSS-treated mice.

infiltration (Figure 5e). To better establish the architecture of tissue sections analyzed in Figure 5, hematoxylin and eosin staining corresponding to these sections is shown in Supplementary Figure S4a-d.

\section{Decreased Inflammation is Accompanied by Increased Levels of TGF- $\beta$ during Experimental Colitis}

TGF- $\beta 1$ is both a pro-fibrotic growth factor and an immunosuppressive mediator that acts through various 


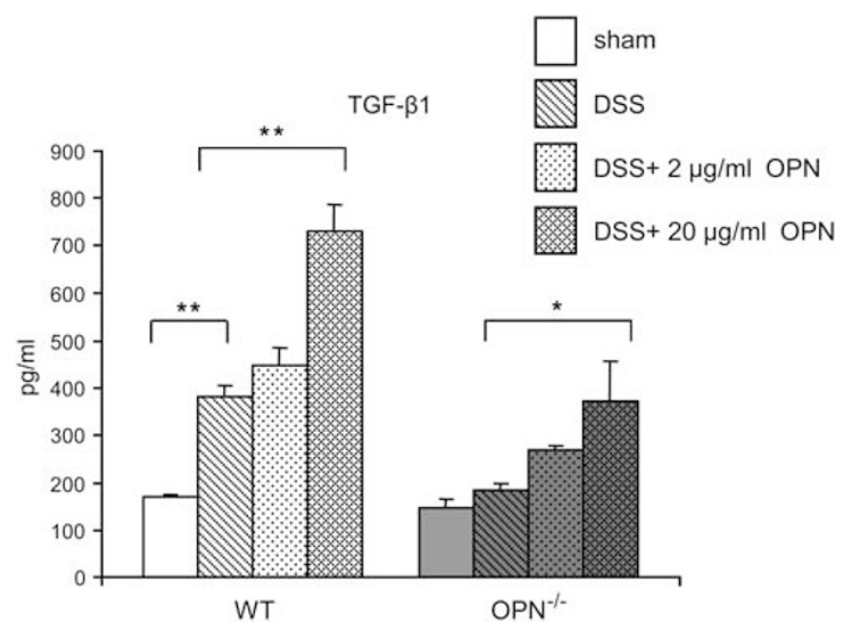

Figure 6 Increased TGF- $\beta 1$ levels in colon tissues upon administration of milk OPN. During DSS-induced colitis, WT colons exhibited higher levels of TGF- $\left.\beta 1{ }^{* *} P<0.001\right)$, which was not seen in the OPN ${ }^{-1-}$ colons. Both WT and $\mathrm{OPN}^{-1-}$ mice that were administered milk OPN exhibited even higher levels of TGF- $\beta 1$ in colon tissue (WT, ${ }^{* *} P<0.001 ; \mathrm{OPN}^{-1-},{ }^{\star} P<0.05, n=5$ ).

mechanisms, including downregulation of pro-inflammatory cytokines. Therefore, TGF- $\beta 1$ expression in colon tissue lysates was compared among the OPN treatment and control groups. Colon tissue from DSS-treated WT mice, but not from $\mathrm{OPN}^{-1-}$ mice, showed elevated levels of TGF- $\beta 1$ (Figure 6; $P<0.001$ ). Yet, when mice were administered $20 \mu \mathrm{g} / \mathrm{ml}$ milk OPN, the DSS-treated mouse colons from both WT and $\mathrm{OPN}^{-1-}$ mice had even greater levels of TGF$\beta 1$ than those of DSS-treated mice that did not receive exogenous OPN (Figure 6; WT, $P<0.001$; $\mathrm{OPN}^{-1-}, P<0.05$, $n=5)$.

\section{Decreased Inflammation upon OPN Administration is Coincident with Diminution of Pro-inflammatory Mediators}

Extracts of gut tissues were analyzed for the presence of proinflammatory cytokines using cytokine antibody arrays. Values were calculated as a percentage of the positive controls $(100 \%)$ in each array. DSS-treated WT colons exhibited significantly greater amounts (2- to 10-fold) of G-CSF, IFN- $\gamma$, M-CSF, TNF- $\alpha$, MIG, and RANTES than those of the sham group (Figure 7). Administration of $20 \mu \mathrm{g} / \mathrm{ml}$ OPN to DSS-treated WT colons reduced the levels of these inflammatory mediators to that of the sham group, which received no DSS.

\section{BSA and r-OPN Fail to Reproduce the Beneficial Effects of Milk OPN}

In order to exclude the fact that the beneficial effects of OPN in experimental colitis were due to a general effect of administering exogenous protein in drinking water, a comparison of BSA and OPN administration was assessed in DSStreated mice. As before, $20 \mu \mathrm{g} / \mathrm{ml}$ OPN decreased the clinical signs of colitis (DAI scores, neutrophils) (Supplementary

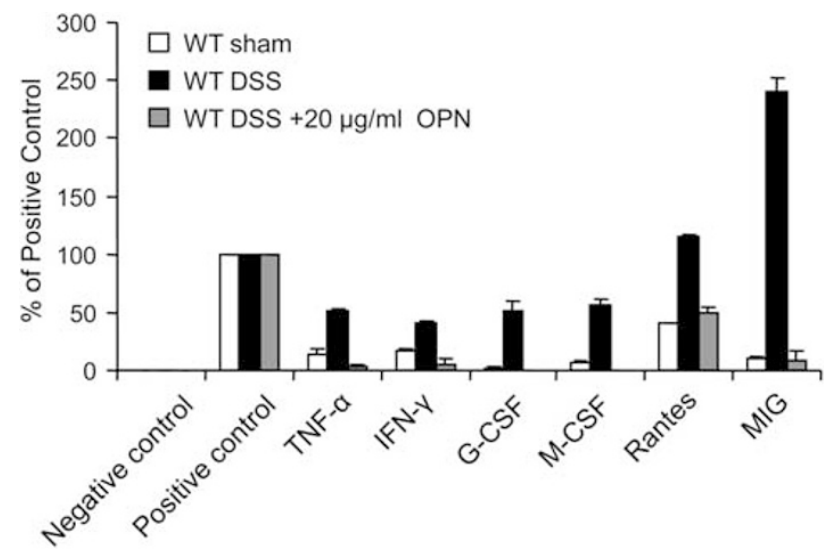

Figure 7 Pro-inflammatory cytokines in the colon tissue. Values on the $y$-axis were calculated as a percentage of the positive control (100\%) in each array. In colon tissue extracts of WT DSS-treated mice, administration of $20 \mu \mathrm{g} / \mathrm{ml}$ OPN reduced the amount of TNF- $\alpha$, IFN- $\gamma$, G-CSF, M-CSF, RANTES, and MIG to control levels.

Figure S1a, b; $P<0.05, n=5)$. In contrast, $20 \mu \mathrm{g} / \mathrm{ml} \mathrm{BSA} \mathrm{had}$ no effect in modulating the DSS-induced colitis (Supplementary Figure S1a, b).

As it is known that various cellular responses to OPN are due to its post-translational modifications, ${ }^{35}$ disease progression of experimental colitis was analyzed in DSS-treated mice administered either milk OPN or r-OPN, which contains no post-translational modifications. After 4 days of DSS treatment, the mice administered milk OPN showed lower scores for the DAI than those administered r-OPN (Figure 8a; $P<0.05, n=5)$. Peripheral blood analysis showed decreased levels of RBC and higher levels of WBC in the r-OPN group, indicating blood loss and acute inflammation (Figure 8b). Moreover, r-OPN failed to reduce neutrophil and lymphocyte counts as observed for milk OPN (Figure 8c). These results suggest that the post-translational modifications of milk OPN, such as phosphorylation, ${ }^{35}$ are crucial for achieving the beneficial effects of exogenous OPN in DSS-induced colitis.

\section{DISCUSSION}

\section{Bovine Milk OPN Attenuates Acute DSS-Induced Colitis}

In a previous study, we found a greater susceptibility of $\mathrm{OPN}^{-1-}$ than WT mice to DSS-induced colitis. ${ }^{16}$ This finding led us to ask whether the administration of exogenous OPN may have a protective effect during DSS-induced colitis. Our major findings in this study support this contention. We found that OPN $(20 \mu \mathrm{g} / \mathrm{ml})$ introduced for 8 days dissolved in the drinking water was detected in the colon mucosa (Figure 2). It ameliorated DSS-induced colitis in mice by diminishing signs of disease and by decreasing fecal occult blood loss, peripheral blood neutrophils, colon mucosa neutrophils, macrophages, and pro-inflammatory cytokines. Yet, others have shown that abrogation of the interaction between OPN and its receptors by antibodies 


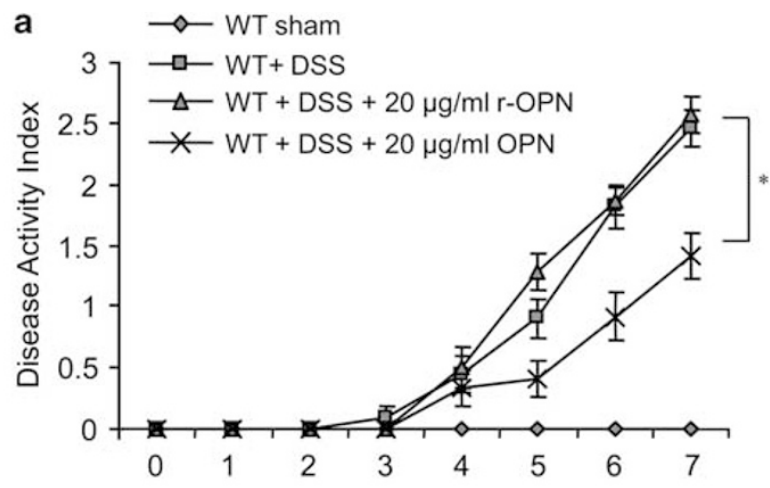

b

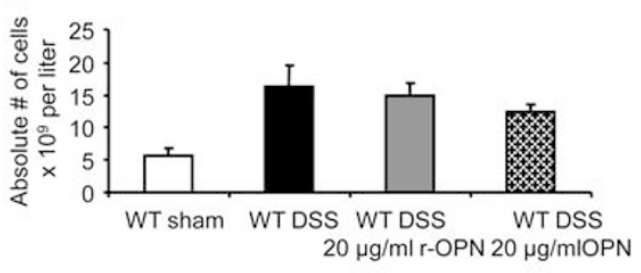

C

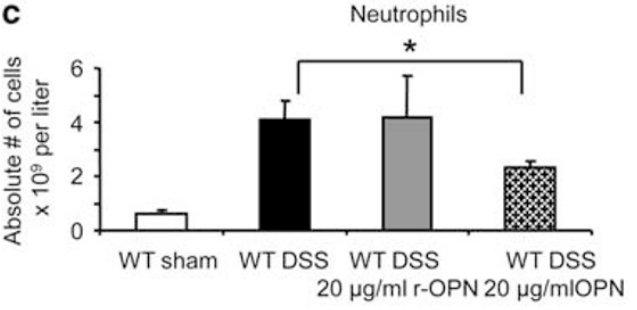

RBC

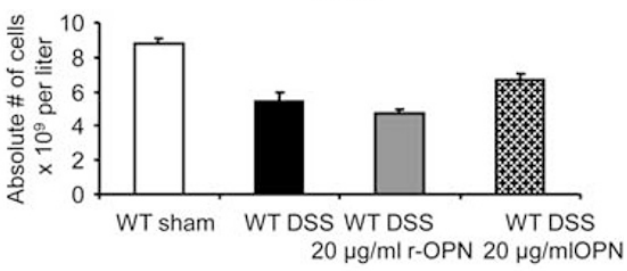

Lymphocytes

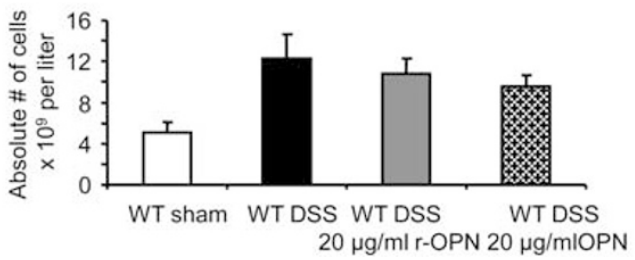

Figure 8 Lack of protection upon administration of recombinant OPN (r-OPN). (a) DSS-treated mice administered $20 \mu \mathrm{g} / \mathrm{ml}$ milk OPN exhibited less severe clinical signs of colitis than the mice administered $20 \mu \mathrm{g} / \mathrm{ml} \mathrm{r-OPN}$ and DSS or DSS alone $\left({ }^{*} P<0.05, n=5\right)$. (b) Peripheral blood analysis found decreased levels of RBC and high levels of WBC in the r-OPN group, indicating blood loss and acute inflammation. (c) r-OPN failed to reduce neutrophil counts compared with milk OPN ( $\left.{ }^{*}<<0.05, n=5\right)$ after 8 days of treatment. Neither OPN preparation affected the lymphocyte count significantly.

specific for the SLAYGLR domain of OPN resulted in the amelioration of inflammatory diseases such as rheumatoid arthritis, hepatitis, and inflammatory ocular disease. ${ }^{36-39}$ Our findings suggest that the pathogenesis of acute colitis induced by DSS is different from that of these other inflammatory diseases, as it is a mucosal disease in which an intact mucosal epithelial barrier is required to combat intermittent bacterial influx. Therefore, in contrast to DSS-induced chronic colitis, in which OPN may induce polarization of the type 1 helper T-cell immune response to cause increased inflammation, ${ }^{40}$ OPN may actually attenuate inflammation in DSS-induced acute colitis by contributing to the resolution of a deregulated innate immune response in the colon. Yet, there is a possibility that stimulation of adaptive immunity could account for some of the responses to bovine milk OPN administration.

\section{Bovine Milk OPN Decreases Destructive Capacity of Neutrophils by Activating Macrophages}

In the presence of OPN, macrophages infiltrating the injured mucosal tissues in early stages of acute inflammation help the neutrophils to combat invading pathogens, while concomitantly limiting the amount of damage by the neutrophils. ${ }^{41}$ We have shown that the absence of OPN expression in $\mathrm{OPN}^{-1-}$ mice leads to increased destructive activity of neutrophils and improper differentiation of macrophages. ${ }^{16}$ However, we have also shown that the expression of OPN is not required for neutrophil destructive capacity. ${ }^{17}$ This increased neutrophil activity may be due to slow clearance by $\mathrm{OPN}^{-1-}$ macrophages, ${ }^{42}$ which display impaired migration, ${ }^{18}$ suggesting that they may also have reduced phagocytic activity in vivo. Our most recent data show that the oral administration of $20 \mu \mathrm{g} / \mathrm{ml}$ of bovine milk OPN led to a reduction in neutrophil activity (Figure 5a) accompanied by an increase in the TGF- $\beta 1$ expression (Figure 6). These results suggest that exogenous OPN may act by restoring macrophage activity.

Effective elimination of neutrophils is a prerequisite for resolution of the inflammatory response. ${ }^{43}$ One possibility in our colitis model is that exogenous OPN may contribute to the termination of inflammation by activating macrophages to take up apoptotic neutrophils, thereby leading to 
neutrophil clearance and the release of anti-inflammatory and reparative cytokines, such as TGF- $\beta 1{ }^{44}$ Both in vitro and in vivo evidence suggest that secretion of TGF- $\beta 1$ by macrophages can suppress pro-inflammatory signaling from Tolllike receptors, further stimulating tissue repair. ${ }^{45,46}$

The attenuation of an inflammatory reaction coincides with the departure of macrophages through the lymphatics. ${ }^{43,47,48}$ The tissue mononuclear cell population (macrophages and lymphocytes) returns to normal preinflammation density and phenotypes. ${ }^{49}$ In support of this concept, our immunohistochemistry analysis of colon sections indicates that oral administration of milk OPN decreased the macrophage population during DSS-induced colitis (Figure 5e). Consequently, it is possible that once apoptosis of leukocytes and resident cells is engaged (an early event), subsequent uptake of apoptotic cells would cause a switch in macrophage phenotype from activated or injurious to reparative or migratory. Such a shift would also be expected to diminish the local production of pro-inflammatory cytokines, as we observed in our data set (Figure 7). Exogenous milk OPN appeared to promote a more confined sequence of protective inflammatory responses, while limiting the intensity of the acute DSS-induced colitis.

\section{TGF- $\beta 1$, Restitution of the Mucosal Epithelial Barrier, and Healing}

The intestinal mucosal barrier is formed by a monolayer of tightly joined epithelial cells that most often becomes disrupted during colitis. It has been shown that the intestinal mucosa promotes epithelial restitution after mucosal injury through the increased production of bioactive TGF- $\beta 1$ by the epithelial cells ${ }^{21}$ and by subepithelial myofibroblasts. ${ }^{50}$ For example, epithelial monolayers pretreated with TGF- $\beta 1$ completely abrogated the barrier-disrupting effect of the intestinal pathogen Cryptosporidium parvum oocysts. ${ }^{51}$ In this study of experimental colitis, the beneficial effects of administering $20 \mu \mathrm{g} / \mathrm{ml}$ milk OPN was accompanied by a significant increase in TGF- $\beta 1$ level in both $\mathrm{OPN}^{-1-}$ and WT mice (Figure 6). The increase in TGF- $\beta 1$ level may have contributed to the maintenance of intestinal barrier integrity and intestinal healing in the mice that experienced less tissue destruction.

\section{OPN Modification may be Crucial for its Attenuation of DSS-Induced Colitis}

Post-translational phosphorylation of OPN has a significant impact on the biological functions of this protein. ${ }^{35}$ Ashkar et $a l^{13}$ reported that phosphorylation of the $\mathrm{N}$-terminal domain of OPN is required for RGD- $\beta_{3}$-integrin recognition, and subsequent induction of interleukin-12 expression in murine macrophages. Similarly, phosphorylation of OPN is required for its stimulation of RGD-mediated spreading and activation of macrophages. ${ }^{52}$ Moreover, Al-Shami et al $l^{53}$ have shown that OPN induces trophoblastic cell migration, which is a process that depends on the level of phosphorylation of
OPN. It can be noted that the r-OPN that we used in our study of experimental colitis, derived from the rat OPN sequence, did not promote the protective effects that were clearly associated with administration of bovine milk OPN, which is highly phosphorylated. ${ }^{54}$ Although no detrimental effects were associated with the use of the r-OPN, its lack of protective effects may be explained by its freedom from posttranslational modification. Alternatively, the different results for the two forms of OPN could have been due to their distinct phylogenetic source; divergence in primary sequence may have contributed to altered function. However, the functional domains of OPN are normally well conserved among species, ${ }^{55}$ and it is more likely that such differences are due to the degree or position of phosphorylation.

\section{Does the Efficacy of Exogenous Milk OPN Require Expression of Endogenous OPN?}

In this study, we found that administration of milk OPN diminished the damaging effects of DSS more in the WT than in the $\mathrm{OPN}^{-1-}$ mice. Although the $\mathrm{OPN}^{-1-}$ mice, which express no endogenous OPN, experienced marginal protection, and therefore may have required a greater dose, we propose that intracellular OPN may be a critical cofactor for mediating the physiological responses required for the attenuation of DSS-induced colitis. Evidence to support this hypothesis comes from a number of studies that explored the relationship of CD44 and OPN. The intracellular form of OPN has a peri-membranous distribution, and it colocalizes with CD44 and ezrin-radixin-moesin proteins in migrating embryonic fibroblasts, activated macrophages, and metastatic breast cancer cells. ${ }^{56-58}$ Impaired chemotaxis in $\mathrm{OPN}^{-1-}$ macrophages ${ }^{18}$ and osteoclasts ${ }^{59}$ has been associated with reduced cell surface expression of CD44. Moreover, although expression of OPN is evidently required for the recruitment of CD44 to the cell surface in macrophages and osteoclasts, ${ }^{58-60}$ this requirement is not evident in neutrophils. ${ }^{61}$ The ligation of CD44 by OPN mediates chemotaxis and adhesion of fibroblasts $^{62}$ and the downregulation of interleukin-10 (IL)-10 expression in peritoneal macrophages. ${ }^{13}$ Furthermore, it has been suggested that the extracellular OPN can provide temporary CD44 or more substantial integrin attachment complexes that are required for the motility and the chemotactic functions of migrating cells. ${ }^{55}$ Consistent with this concept, Lee et $a l^{63}$ showed that an OPN-CD44 interaction is able to increase integrin adhesion by activation of integrins through inside-out signaling, resulting in increased cell survival. Therefore, it is conceivable that macrophages of $\mathrm{OPN}^{-1-}$ mice may not be fully activated in the presence of exogenous OPN, which could impair the phagocytosis of neutrophils by the macrophages. Indeed, the administration of exogenous OPN led to only a minor, insignificant decrease in MPO activity of tissues from the $\mathrm{OPN}^{-1-}$ mice (Figure 5a).

In summary, this study shows that the administration of bovine milk OPN attenuates DSS acute colitis. The protective 
effect seems to depend on a post-translationally modified form of OPN, and it is diminished in mice that are genetically deficient in endogenous OPN expression. The mechanism by which exogenous OPN attenuates colitis may be due to (1) the modulation of the number of neutrophils and their destructive activities, (2) decreased pro-inflammatory cytokine release, and (3) restitution of the epithelial barrier through increased local expression of TGF- $\beta 1$, all potentially affected through macrophage interactions.

Supplementary Information accompanies the paper on the Laboratory Investigation website (http://www.laboratoryinvestigation.org)

\section{ACKNOWLEDGEMENTS}

This paper is dedicated to the memory of our senior author, respected colleague, and friend Jaro Sodek, who was instrumental in the conception, research design, conduct of the experiments to test the hypothesis, and interpretation of the early data leading to this submission. We thank Drs. Philip M. Sherman and Susan Rittling for their advice and Adeline Koh and Manju Bansal for technical support. This study was supported by CIHR Strategic Training Fellowship STP-53877, a grant from the Dairy Farmers of Canada and a CIHR/IMHA grant.

\section{DISCLOSURE/CONFLICT OF INTEREST}

The authors declare no conflict of interest.

1. Orlando RC. Mechanisms of epithelial injury and inflammation in gastrointestinal diseases. Rev Gastroenterol Disord 2002;2(Suppl 2): S2-S8.

2. Podolsky DK. The current future understanding of inflammatory bowel disease. Best Pract Res Clin Gastroenterol 2002;16:933-943.

3. Loftus Jr EV. Clinical epidemiology of inflammatory bowel disease: incidence, prevalence, and environmental influences.

Gastroenterology 2004;126:1504-1517.

4. Stevceva L, Pavli P, Husband AJ, et al. The inflammatory infiltrate in the acute stage of the dextran sulphate sodium induced colitis: B cell response differs depending on the percentage of DSS used to induce it. BMC Clin Pathol 2001;1:3.

5. Hume DA, Allan W, Hogan PG, et al. Immunohistochemical characterisation of macrophages in human liver and gastrointestinal tract: expression of CD4, HLA-DR, OKM1, and the mature macrophage marker 25F9 in normal and diseased tissue. J Leukoc Biol 1987;42: 474-484.

6. Oshitani N, Campbell A, Kitano A, et al. In situ comparison of phenotypical and functional activity of infiltrating cells in ulcerative colitis mucosa. J Pathol 1996;178:95-99.

7. Britigan BE, Coffman TJ, Adelberg DR, et al. Mononuclear phagocytes have the potential for sustained hydroxyl radical production. Use of spin-trapping techniques to investigate mononuclear phagocyte free radical production. J Exp Med 1988;168:2367-2372.

8. Okayasu I, Hatakeyama S, Yamada M, et al. A novel method in the induction of reliable experimental acute and chronic ulcerative colitis in mice. Gastroenterology 1990;98:694-702.

9. Cooper HS, Murthy SN, Shah RS, et al. Clinicopathologic study of dextran sulfate sodium experimental murine colitis. Lab Invest 1993;69:238-249.

10. Murthy SN, Cooper HS, Shim H, et al. Treatment of dextran sulfate sodium-induced murine colitis by intracolonic cyclosporin. Dig Dis Sci 1993;38:1722-1734.

11. Elson CO, Cong Y, Weaver CT, et al. Monoclonal anti-interleukin 23 reverses active colitis in a $\mathrm{T}$ cell-mediated model in mice. Gastroenterology 2007;132:2359-2370.

12. Wang KX, Denhardt DT. Osteopontin: role in immune regulation and stress responses. Cytokine Growth Factor Rev 2008;19:333-345.

13. Ashkar S, Weber GF, Panoutsakopoulou V, et al. Eta-1 (osteopontin): an early component of type-1 (cell-mediated) immunity. Science 2000;287:860-864.
14. O'Regan A, Berman JS. Osteopontin: a key cytokine in cell-mediated and granulomatous inflammation. Int J Exp Pathol 2000;81: 373-390.

15. Kawamura $\mathrm{K}$, lyonaga $\mathrm{K}$, Ichiyasu $\mathrm{H}$, et al. Differentiation, maturation, and survival of dendritic cells by osteopontin regulation. Clin Diagn Lab Immunol 2005;12:206-212.

16. Da Silva AP, Pollett A, Rittling SR, et al. Exacerbated tissue destruction in DSS-induced acute colitis of OPN-null mice is associated with downregulation of TNF-alpha expression and non-programmed cell death. J Cell Physiol 2006;208:629-639.

17. Koh A, da Silva AP, Bansal AK, et al. Role of osteopontin in neutrophil function. Immunology 2007;122:466-475.

18. Zhu B, Suzuki K, Goldberg HA, et al. Osteopontin modulates CD44dependent chemotaxis of peritoneal macrophages through G-proteincoupled receptors: evidence of a role for an intracellular form of osteopontin. J Cell Physiol 2004;198:155-167.

19. Rollo EE, Denhardt DT. Differential effects of osteopontin on the cytotoxic activity of macrophages from young and old mice. Immunology 1996;88:642-647.

20. McKee MD, Nanci A. Secretion of osteopontin by macrophages and its accumulation at tissue surfaces during wound healing in mineralized tissues: a potential requirement for macrophage adhesion and phagocytosis. Anat Rec 1996;245:394-409.

21. Dignass AU, Podolsky DK. Cytokine modulation of intestinal epithelial cell restitution: central role of transforming growth factor beta. Gastroenterology 1993;105:1323-1332.

22. Desmouliere A. Factors influencing myofibroblast differentiation during wound healing and fibrosis. Cell Biol Int 1995;19:471-476.

23. Jelaska A, Korn JH. Role of apoptosis and transforming growth factor beta1 in fibroblast selection and activation in systemic sclerosis. Arthritis Rheum 2000;43:2230-2239.

24. Zohar R, Zhu B, Liu P, et al. Increased cell death in osteopontindeficient cardiac fibroblasts occurs by a caspase-3independent pathway. Am J Physiol Heart Circ Physiol 2004;287:H1730-H1739.

25. Miyazaki Y, Tashiro T, Higuchi Y, et al. Expression of osteopontin in a macrophage cell line and in transgenic mice with pulmonary fibrosis resulting from the lung expression of a tumor necrosis factor-alpha transgene. Ann N Y Acad Sci 1995;760:334-341.

26. Noiri E, Dickman K, Miller F, et al. Reduced tolerance to acute renal ischemia in mice with a targeted disruption of the osteopontin gene. Kidney Int 1999;56:74-82.

27. Chabas D, Baranzini SE, Mitchell D, et al. The influence of the proinflammatory cytokine, osteopontin, on autoimmune demyelinating disease. Science 2001;294:1731-1735.

28. O'Regan AW, Hayden JM, Body S, et al. Abnormal pulmonary granuloma formation in osteopontin-deficient mice. Am J Respir Crit Care Med 2001;164:2243-2247.

29. Yumoto K, Ishijima M, Rittling SR, et al. Osteopontin deficiency protects joints against destruction in anti-type II collagen antibody-induced arthritis in mice. Proc Natl Acad Sci USA 2002;99:4556-4561.

30. Sorensen ES, Petersen TE. Purification and characterization of three proteins isolated from the proteose peptone fraction of bovine milk. J Dairy Res 1993;60:189-197.

31. Tye CE, Rattray KR, Warner KJ, et al. Delineation of the hydroxyapatitenucleating domains of bone sialoprotein. J Biol Chem 2003;278: 7949-7955.

32. Rittling SR, Matsumoto HN, McKee MD, et al. Mice lacking osteopontin show normal development and bone structure but display altered osteoclast formation in vitro. J Bone Miner Res 1998;13:1101-1111.

33. Hartmann G, Bidlingmaier C, Siegmund B, et al. Specific type IV phosphodiesterase inhibitor rolipram mitigates experimental colitis in mice. J Pharmacol Exp Ther 2000;292:22-30.

34. Zhang Q, Domenicucci C, Goldberg HA, et al. Characterization of fetal porcine bone sialoproteins, secreted phosphoprotein I (SPPI, osteopontin), bone sialoprotein, and a 23-kDa glycoprotein. Demonstration that the $23-\mathrm{kDa}$ glycoprotein is derived from the carboxyl terminus of SPPI. J Biol Chem 1990;265:7583-7589.

35. Kazanecki CC, Uzwiak DJ, Denhardt DT. Control of osteopontin signaling and function by post-translational phosphorylation and protein folding. J Cell Biochem 2007;102:912-924. 
36. Yamamoto $N$, Sakai $F$, Kon $S$, et al. Essential role of the cryptic epitope SLAYGLR within osteopontin in a murine model of rheumatoid arthritis. J Clin Invest 2003;112:181-188.

37. Diao H, Kon S, Iwabuchi K, et al. Osteopontin as a mediator of NKT cell function in T cell-mediated liver diseases. Immunity 2004;21:539-550.

38. Kitamura M, Iwabuchi K, Kitaichi N, et al. Osteopontin aggravates experimental autoimmune uveoretinitis in mice. J Immunol 2007;178:6567-6572.

39. Saito $Y$, Kon S, Fujiwara $Y$, et al. Osteopontin small interfering RNA protects mice from fulminant hepatitis. Hum Gene Ther 2007;18:1205-1214.

40. Heilmann K, Hoffmann U, Witte E, et al. Osteopontin as two-sided mediator of intestinal inflammation. J Cell Mol Med 2008;13:1162-1174.

41. Sodek J, Batista da Silva AP, Zohar R. Osteopontin and mucosal protection. J Dent Res 2006;85:404-415.

42. Hart SP, Ross JA, Ross K, et al. Molecular characterization of the surface of apoptotic neutrophils: implications for functional downregulation and recognition by phagocytes. Cell Death Differ 2000;7:493-503.

43. Savill J. Apoptosis in resolution of inflammation. J Leukoc Biol 1997;61:375-380.

44. Barker RN, Erwig L, Pearce WP, et al. Differential effects of necrotic or apoptotic cell uptake on antigen presentation by macrophages. Pathobiology 1999;67:302-305.

45. Huynh ML, Fadok VA, Henson PM. Phosphatidylserine-dependent ingestion of apoptotic cells promotes TGF-beta1 secretion and the resolution of inflammation. J Clin Invest 2002;109:41-50.

46. Lucas M, Stuart LM, Savill J, et al. Apoptotic cells and innate immune stimuli combine to regulate macrophage cytokine secretion. J Immunol 2003;171:2610-2615.

47. Nathan C. Inducible nitric oxide synthase in the tuberculous human lung. Am J Respir Crit Care Med 2002;166:130-131.

48. Lawrence T, Willoughby DA, Gilroy DW. Anti-inflammatory lipid mediators and insights into the resolution of inflammation. Nat Rev Immunol 2002;2:787-795.

49. Serhan CN, Savill J. Resolution of inflammation: the beginning programs the end. Nat Immunol 2005;6:1191-1197.

50. McKaig BC, Makh SS, Hawkey CJ, et al. Normal human colonic subepithelial myofibroblasts enhance epithelial migration (restitution) via TGF-beta3. Am J Physiol 1999;276(5 Part 1):G1087-G1093.
51. Roche JK, Martins CA, Cosme $\mathrm{R}$, et al. Transforming growth factor beta1 ameliorates intestinal epithelial barrier disruption by Cryptosporidium parvum in vitro in the absence of mucosal $T$ lymphocytes. Infect Immun 2000;68:5635-5644.

52. Weber GF, Zawaideh S, Hikita S, et al. Phosphorylation-dependent interaction of osteopontin with its receptors regulates macrophage migration and activation. J Leukoc Biol 2002;72:752-761.

53. Al-Shami R, Sorensen ES, Ek-Rylander B, et al. Phosphorylated osteopontin promotes migration of human choriocarcinoma cells via a p70 S6 kinase-dependent pathway. J Cell Biochem 2005;94:1218-1233.

54. Sorensen ES, Hojrup P, Petersen TE. Posttranslational modifications of bovine osteopontin: identification of twenty-eight phosphorylation and three O-glycosylation sites. Protein Sci 1995;4:2040-2049.

55. Sodek J, Ganss B, McKee MD. Osteopontin. Crit Rev Oral Biol Med 2000;11:279-303.

56. Zohar R, Cheifetz S, McCulloch CA, et al. Analysis of intracellular osteopontin as a marker of osteoblastic cell differentiation and mesenchymal cell migration. Eur J Oral Sci 1998;106(Suppl 1):401-407.

57. Zohar R, Suzuki N, Suzuki K, et al. Intracellular osteopontin is an integral component of the CD44-ERM complex involved in cell migration. J Cell Physiol 2000;184:118-130.

58. Suzuki K, Zhu B, Rittling SR, et al. Colocalization of intracellular osteopontin with CD44 is associated with migration, cell fusion, and resorption in osteoclasts. J Bone Miner Res 2002;17:1486-1497.

59. Chellaiah MA, Biswas RS, Rittling SR, et al. Rho-dependent Rho kinase activation increases CD44 surface expression and bone resorption in osteoclasts. J Biol Chem 2003;278:29086-29097.

60. Chellaiah MA, Kizer N, Biswas R, et al. Osteopontin deficiency produces osteoclast dysfunction due to reduced CD44 surface expression. Mol Biol Cell 2003;14:173-189.

61. Alstergren $\mathrm{P}$, Zhu B, Glogauer M, et al. Polarization and directed migration of murine neutrophils is dependent on cell surface expression of CD44. Cell Immunol 2004;231:146-157.

62. Denhardt DT, Giachelli CM, Rittling SR. Role of osteopontin in cellular signaling and toxicant injury. Annu Rev Pharmacol Toxicol 2001;41:723-749.

63. Lee JL, Wang MJ, Sudhir PR, et al. Osteopontin promotes integrin activation through outside-in and inside-out mechanisms: OPN-CD44V interaction enhances survival in gastrointestinal cancer cells. Cancer Res 2007;67:2089-2097. 